\title{
Tax Preferential, R\&D Investment and Enterprise Performance-An Empirical Study Based on Mediating Effect
}

\author{
WANG Yajie \\ School of Economics and Management, Beijing Jiaotong University, Beijing, China
}

511850114@qq.com

Keywords: Tax incentives, Corporate R\&D investment, Corporate performance, Mediating effect.

\begin{abstract}
This paper takes 410 companies listed on GEM in 2015-2017 as a sample, and uses R\&D investment as a mediator to study the impact of tax incentives on firm performance and explore the mediating effects of $R \& D$ investment. The empirical results show that tax incentives have a significant positive effect on corporate performance and $R \& D$ investment; corporate $R \& D$ investment has a partial mediating effect between tax incentives and firm performance. Therefore, GEM listed companies should effectively use tax incentives and increase R\&D investment to improve corporate performance.
\end{abstract}

\section{税收优惠、研发投入与企业绩效一一基于中介效应的实证研究}

\author{
王亚洁 \\ 北京交通大学经济管理学院, 北京, 中国 \\ 511850114@qq.com
}

关键词：税收优惠，企业研发投入，企业绩效，中介效应

中文摘要. 本文以2015-2017年410家创业板上市公司为样本, 以研发投入为中介变量, 研究税 收优惠对企业绩效的影响, 并研究研发投入的中介作用。实证结果表明: 税收优惠与企业绩 效显著正相关, 税收优惠对研发投入产生显著的积极影响; 企业研发投入在税收优惠与企业 绩效之间产生部分中介效应。因此, 创业板上市公司应当有效利用税收优惠政策, 加大研发 投入以提升企业绩效。

\section{1. 引言}

自党的十八届会议召开以来，“大众创业，人人创新”的浪潮涌来，各类企业都在不断加 大研发投入，技术创新成为推动国家经济增长的关键环节。同时，技术创新也有利于提高企 业绩效。 ${ }^{1}$ 对于创业板上市公司而言，保持市场竞争力的主要方式是通过加大对新技术的研发 投入。近年来，我国陆续推出了一系列企业税收优惠政策以鼓励创业板上市公司的研发投入 以及企业绩效的提升。政府的税收优惠政策能够降低公司的资金占用成本，降低融资风险。 税收优惠政策也会引起企业对研发投入的重视，加大研发投入力度，从而提高本产品市场竞 争力, 提升企业绩效。以往学者大多研究税收优惠、研发投入与企业绩效的两者关系, 并没 有进一步研究其内在逻辑关系。基于此, 本文在研究税收优惠与企业绩效的关系基础上, 引 入研发投入这一中介变量，研究税收优惠如何通过影响研发投入，从而对企业绩效产生影响 的内在机理，并为政府进一步完善税收激励政策提供有利借鉴。 


\section{2. 文献回顾与研究假设}

\section{1 税收优惠与企业绩效}

创业板上市公司多数为高科技企业，研发投入是企业较为重要的支出。研发投入能够提 高企业的竞争能力, 但由于研发活动的风险较大，增加了企业的经营风险。针对创业板上市 公司的情况, 政府设定了税收优惠政策, 能够提高企业的净利润, 提高了企业的绩效, 同时, 可以激励企业不断地进行研发活动。

目前学者普遍认为税负与企业经营业绩负相关，税收优惠能够降低税负，对企业绩效的 影响是正向的。林文婷等 (2012) 2 实证研究发现, 通过所得税的影响, 税收优惠提升了企业 绩效。李香菊等 (2014) ${ }^{3}$ 实证发现, 实际税负会对企业经营绩效产生明显的负向影响。江猛 等 (2016) 4 实证研究发现, 合理避税能够改善企业的经营绩效, 消极避税会损害企业的经营 绩效。基于以上观点, 本文提出如下假设:

H1：税收优惠对创业板上市公司的企业绩效有正向影响。

\section{2 税收优惠与研发投入}

税收优惠是政府激励企业扩大研发投入的重要方式之一，通过一系列税收优惠政策，如 减免税、优惠税率、退税政策、加计扣除和税收抵免等，降低了企业研发实际成本，提高企 业净利润。同时，税收优惠为企业自主创新提供了保障，提高企业研发的风险承受能力。大

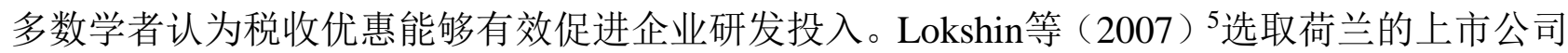
为样本, 实证研究发现, 税收优惠能够有效降低企业研发成本, 从而促进企业加大研发投入。 马伟红 (2011) ${ }^{6}$ 以中小企业为研究对象, 实证研究发现税收优惠对企业的研发投入具有正向 的影响。李传喜等（2016） ${ }^{7}$ 以高新技术企业数据为样本, 实证研究发现税收优惠政策有利于 企业加大研发投入。基于此，本文提出如下假设:

$\mathrm{H} 2$ ：税收优惠促进了创业板上市公司的研发投入。

\section{3 税收优惠、企业研发投入与企业绩效}

目前学者针对税收优惠、研发投入与企业绩效的两者之间的研究较多，从整体上分析三 者之间的关系的研究较为少见。探究研发投入在税收优惠政策和企业绩效之间是否存在中介 效应，有利于完善税收优惠政策和研发创新的政策制定，并对公司绩效产生积极的影响。

因为创业板上市公司本身的性质，进行研发创新是必不可少的一项活动。我国政府颁布 了一系列的税收优惠政策，降低了公司的实际税负，为公司的研发投入活动提供了资金支持。 公司利用研发投入吸引科技人才，研发新工艺、新产品，进而提升企业绩效。所以，本文认 为通过研发投入的实施，税收优惠政策对企业绩效产生影响。因此，提出如下假设：

H3：对创业板上市公司而言，企业研发投入在税收优惠与企业绩效之间产生中介效应。

\section{3. 实证检验}

\section{1 样本选择与数据来源}

本文选取 2015年至 2017 年创业板的上市企业数据为研究样本, 为保证研究数据的可靠 性, 本文剔除了重要解释变量缺失的数据, 最终选择 410 家公司作为研究样本。研究的数据通 过CSMAR数据库整理得出,并利用STATA14等软件对相关数据进行了处理和检验。

\section{2 模型设计和变量定义}

本文参照温忠麟8等中介效应理论，建立如下三个逐步回归检验模型，进行回归检验：

$$
\begin{gathered}
R O E_{i, t}=\beta_{0}+\beta_{1} E_{T R}+R_{i, t}+\beta_{2} \operatorname{SIZE}_{i, t}+\beta_{3} \text { CASH }_{i, t}+\beta_{4} L E V_{i, t}+\beta_{5} \text { GROW }_{i, t}+\beta_{6} L S P_{i, t}+\varepsilon_{i, t} \\
R D_{i, t}=\beta_{0}+\beta_{1} E T R_{i, t}+\beta_{2} \operatorname{SIZE}_{i, t}+\beta_{3} \text { CASH }_{i, t}+\beta_{4} L E V_{i, t}+\beta_{5} \text { GROW }_{i, t}+\beta_{6} L S P_{i, t}+\varepsilon_{i, t}
\end{gathered}
$$




$$
R O E_{i, t}=\beta_{0}+\beta_{1} E T R_{i, t}+\beta_{2} R D_{i, t}+\beta_{3} S I Z E_{i, t}+\beta_{4} C A S H_{i, t}+\beta_{5} L E V_{i, t}+\beta_{6} G R O W_{i, t}+\beta_{7} L S P_{i, t}+\varepsilon_{i, t}
$$

其中, $R O E_{i, t}$ 表示第 $\mathrm{i}$ 家企业第 $\mathrm{t}$ 年的绩效水平; $E T R_{i, t}$ 表示 $\mathrm{i}$ 个样本公司第 $\mathrm{t}$ 个年度的实际税 率; $R D_{i, t}$ 表示第 $\mathrm{i}$ 家企业第 $\mathrm{t}$ 年的研发投入强度; 其余变量表示控制变量, $\varepsilon_{i, t}$ 表示随机误差。

上述模型中各变量含义如表1 所示:

表1 变量定义

\begin{tabular}{|c|c|c|c|}
\hline 变量类型 & 变量名称 & 变量符号 & 变量定义 \\
\hline 因变量 & 净资产收益率 & $R O E$ & 净利润 /净资产 \\
\hline 自变量 & 实际税率 & $E T R$ & 所得税费用/利润总额 \\
\hline 中介变量 & 研发投入强度 & $R D$ & 研发投入/营业收入 \\
\hline 控制变量 & 公司规模 & $S I Z E$ & 总资产) \\
\cline { 2 - 5 } & 自由现金流 & $C A S H$ & 经营现金流量净额/总资产 \\
\cline { 2 - 5 } & 资产负债率 & $L E V$ & 负债总额/资产总额 \\
\cline { 2 - 4 } & 营业收入增长率 & $G R O W$ & $\begin{array}{c}\text { (本期营业收入-上期营 } \\
\text { 业收入)/上期营业收入 }\end{array}$ \\
\cline { 2 - 4 } & 第一大股东持股比例 & $L S P$ & 第一大股东持股数/总股数 \\
\hline
\end{tabular}

\section{4. 实证检验}

\section{1 主要变量的描述性统计}

从表 2 可知, 实际税率均值为 0.1475 , 表明创业板上市公司实际负担较低的所得税, 享 有较大的税收优惠力度。研发投入强度的最大值为 $72.75 \%$, 最小值 $0.06 \%$, 均值为 $6.9774 \%$, 能够发现, 创业板上市公司的研发投入存在一定的差异。从控制变量方面, 可以看到企业规 模的最大值为 24.554 , 最小值为 19.05 , 标准差较小, 行业平均水平 21.4383 , 说明创业板上 市公司总体规模较小，且各个企业之间规模差别不大; 企业内部现金流较少，公司之间差异 不大，表明创业板上市公司内部资金不充足; 营业收入增长率为最大值为 16.9082 , 最小值为 -0.8402 , 均值为 0.3461 , 表明创业板上市公司的成长能力存在较大差异; 第一大股东持股比 例, 最大值为 $69.36 \%$, 最小值为 $4.38 \%$, 标准差为 11.878 , 表明各个企业之间存在较大差异。

表2 描述性统计

\begin{tabular}{|c|c|c|c|c|}
\hline 变量 & 最大值 & 最小值 & 标准差 & 均值 \\
\hline $\begin{array}{c}\text { 净资产收益率 } \\
(R O E)\end{array}$ & 27.2838 & -1.5332 & 0.7842 & 0.0794 \\
\hline 实际税率 $(E T R)$ & 25.1305 & -4.0484 & 0.7692 & 0.1475 \\
\hline $\begin{array}{c}\text { 研发投入强度 } \\
(R D)(\%)\end{array}$ & 72.7500 & 0.0600 & 6.1924 & 6.9774 \\
\hline 公司规模 $(S I Z E)$ & 24.5440 & 19.0519 & 0.7851 & 21.4383 \\
\hline $\begin{array}{c}\text { 自由现金流 } \\
(C A S H)\end{array}$ & 3.9619 & -1.9704 & 0.1699 & 0.0371 \\
\hline $\begin{array}{c}\text { 资产负债率 } \\
(L E V)\end{array}$ & 1.0372 & 0.0276 & 0.1711 & 0.3230 \\
\hline $\begin{array}{c}\text { 营业收入增长率 } \\
(G R O W)\end{array}$ & 16.9082 & -0.8402 & 0.7355 & 0.3461 \\
\hline $\begin{array}{c}\text { 第一大股东持股比 } \\
\text { 例 }(L S P)(\%) \text { ( } 69.3600\end{array}$ & 4.3800 & 11.8778 & 29.2233 \\
\hline
\end{tabular}

\section{2 回归结果分析}

（1）列为税收优惠对企业绩效的实证结果, 根据表 3, 实际所得税率与企业绩效显著负 相关, 说明了税收优惠能够提高企业绩效, 所以假设 $\mathrm{H} 1$ 成立。

在模型 (2) 回归结果中, 实际税率与研发投入的相关系数为 -0.172 , 在 $1 \%$ 的显著性水平 
上显著, 即税收优惠与研发投入显著正相关。税收优惠幅度的提升, 会激励企业进行加大研 发投入，假设 $\mathrm{H} 2$ 成立。

在模型 (3) 回归结果中, 实际税率的回归系数为 -0.091 , 模型 (3) 中的回归系数小于模 型（1）中相应的回归系数, 但结果仍然显著。而且, 加入研发投入变量后, 模型的拟合优度 提高。这表明企业研发投入在税收优惠对企业绩效的正向影响中产生了部分中介效应。所以, 假设 H3 成立。

从控制变量来看，内部现金流与企业绩效显著正相关，表明企业内部现金流较充裕时能 够防范并化解因资产负债率过高而带来的风险, 同时有利于提高企业绩效。公司成长能力对 企业绩效产生正向推动作用, 表明高成长性的创业板上市公司能够有效的利用税收优惠政策 来提高企业绩效。

表3 模型多元回归结果

\begin{tabular}{|c|c|c|c|}
\hline 变量 & $(1)$ & $(2)$ & $(3)$ \\
\hline$E T R$ & $-0.086^{* * *}(-5.83)$ & $-0.172^{* * *}(-7.48)$ & $-0.091^{* * *}(-6.02)$ \\
\hline$R D$ & & & $-0.06^{* *}(-4.03)$ \\
\hline$S I Z E$ & $0.001(0.19)$ & $-0.097(-0.4)$ & $0.002^{* *}(0.27)$ \\
\hline$C A S H$ & $0.127^{* * *}(4.83)$ & $-0.057(-1.72)$ & $0.137^{* * *}(4.89)$ \\
\hline$L E V$ & $-0.003(-0.12)$ & $-1.454(-1.59)$ & $-0.012(-0.44)$ \\
\hline GROW & $0.023^{* * *}(5.12)$ & $-1.110^{* *}(-7.74)$ & $0.030^{* * *}(6.75)$ \\
\hline$L S P$ & $0.000(0.3)$ & $-0.055^{* *}(-2.33)$ & $0.001 \quad(0.77)$ \\
\hline$R$-Squared & 0.300 & 0.107 & 0.320 \\
\hline obs & 1230 & 1230 & 1230 \\
\hline
\end{tabular}

注: 括号内为值， * 、 **、***、分别表示在 $10 \% 、 5 \%$ 和 $1 \%$ 的置信水平上显著。

\section{5. 稳健性检验}

为进一步检验实证结果的可靠性, 本研究将总资产净利润率 (ROA) 作为衡量企业绩效 的新变量, 进行上述回归分析, 实证结果如表 4 中显示。结果并未发生明显变化, 即研发投 入在税收优惠对企业绩效的影响中具有中介作用。

表4 稳健性检验

\begin{tabular}{|c|c|c|c|}
\hline 变量 & $(1)$ & $(2)$ & $(3)$ \\
\hline$E T R$ & $-0.056^{* *}(-5.43)$ & $-0.172^{* * *}(-7.48)$ & $-0.078^{* *}(-6.12)$ \\
\hline$R D$ & & & $-0.05^{* *}(-4.23)$ \\
\hline$R$-Squared & 0.320 & 0.107 & 0.325 \\
\hline \\
注: ***、**、 * 分别表示在 $1 \%$ 、 $5 \%$ 和 $10 \%$ 的置信水平上显著, 括号内为t值。
\end{tabular}

\section{6. 结论与建议}

本文以创业板上市公司 2015 到 2017 年的数据为样本, 实证研究了税收优惠对企业绩效 的影响, 并研究了在中介变量研发投入的影响下, 税收优惠对企业绩效的影响。研究发现, 税收优惠可以显著提升企业绩效, 而且可以通过企业研发投入这一个中间变量对其产生间接 激励效应。

根据上文的研究结论, 本文提出以下政策建议:

在目前税收优惠政策的基础上，我国应不断改进创新，加快税收优惠政策的顺利实施， 为企业提供研发投入的保障。其次, 企业自身也要主动地进行研发投入, 重视技术创新, 促 进企业绩效提升。最后, 积极地与高校、科研机构开展合作, 汲取先进的科研经验, 提升研 发成果转化效率。 


\section{References}

[1] ZHOU Bing, XU Hui, REN Zhengliang. Corporate Social Responsibility, Free Cash Flow and Corporate Value_-An Empirical Study Based on Mediating Effect[J].East China Economic Management, 2016, 30(02): 129-135.

[2] Lin Wenting, Pan Xiaozhen. Ownership Structure, Tax Preferential and Enterprise PerformanceAn Empirical Analysis Based on China's Listed Financial Enterprises[J].Zhejiang Finance,2012,(05):56-58.

[3] Li Xiangju, Zhu Yukun. An Empirical Study on Tax Burden and Business Performance of Chinese Mining Enterprises[J].China Population Resources and Environment, 2014, (2): 149-153.

[4] Wang Meng, Xu Jingchang. Corporate Tax Avoidance, Inflation Expectation and Business Performance [J].Accounting Research, 2016, 05: 40-47+95.

[5] B. Lokshin,P. Mohnen.Measuring the effectiveness of R\&D tax credits in the Netherlands[J].UNUMERIT Working paper, 2007,(2):23-25.

[6] Ma Weihong. An Empirical Study on the Competitiveness Evaluation of Small and Medium-sized Board High-tech Enterprises[J]Journal of Nanjing University of Finance and Economics, 2011(5):35-41.

[7] Li Chuanxi, Zhao Xun. Research on the investment effect of financial and tax incentives in China's high-tech enterprises [J].Tax Research, 2016 (02): 105-109.

[8] WEN Zhonglin.ZHANG Lei,HOU Jietai,LIU Hongyun.Intermediary effect test procedure and its application[J].Acta Psychologica Sinica,2004(05):614-620. 